\title{
LEGITIMAÇÃO DE POLÍTICAS CIENTÍFICAS LOCAIS EM FUNÇÃO DE DEMANDAS DE INTERNACIONALIZAÇÃ̃O DA UNIVERSIDADE
}

\author{
Inês Signorini ${ }^{1}$
}

\begin{abstract}
RESUMO: Os objetivos deste artigo são identificar e descrever estratégias de legitimação de políticas científicas voltadas para a internacionalização de uma universidade pública do interior de São Paulo, de 2009 a 2016. O corpus de referência é composto de documentos de divulgação dos discursos oficiais (locais e translocais) sobre o tema, de editais locais para financiamento de pesquisa e de chamadas para cursos e seminários direcionados para a inovação e a internacionalização da pesquisa. Os resultados da análise desse material mostram que as estratégias de internacionalização no período focalizado tiveram também a função de legitimação da gestão e de reprodução do poder institucional e, consequentemente, de reprodução da hierarquização de atores e discursos dentro da instituiçáo. Nessa hierarquização, orientada por critérios e normas próprios dos ranqueamentos internacionais, manteve-se a posição historicamente marginal das ciências humanas, particularmente dos estudos da linguagem nos processos de definição e implementação das políticas locais de internacionalização, inclusive das políticas linguísticas.
\end{abstract}

Palavras-chave: Internacionalização. Universidade pública. Legitimidade política e social. Poder institucional.

${ }^{1}$ Universidade Estadual de Campinas - Campinas (SP), Brasil. E-mail: signor@iel.unicamp.br DOI: 10.1590/CC0101-32622018183571 


\section{Legitimation of local scientific policies due to the internationalization requirements of the university}

ABSTRACT: This article aims to identify and describe strategies to legitimize scientific policies towards the internationalization of a public university in São Paulo countryside, from 2009 to 2016. The reference corpus is comprised of the analysis of official discourses on the subject (local and translocal), local calls for research funding, and for courses and seminars focused on innovation and research internationalization. The results of the analysis of this material show that in internationalization strategies during such focused period also had the role of management and reproduction of institutional power and, consequently, the hierarchy reproduction of actors and discourses within the institution. The importance attributed to rankings, especially the international ones, was maintained in the formulation and legitimation of local stimulus or induction policies for innovation, research and international cooperation. And as far as hierarchies in the institutional field are concerned, criteria and norms peculiar to the international rankings, taken as impartial and objective, explain the historically marginal position of the human sciences, particularly of language studies, in the processes of definition and implementation of local internationalization policies, including language policies.

Keywords: Internationalization. Public university. Political and social legitimacy. Institutional power.

\section{INTRODUÇÃO}

Os objetivos deste artigo são identificar e descrever estratégias de legitimação de políticas científicas voltadas para a internacionalização de uma universidade pública paulista no período compreendido pelos dois últimos reitorados (2009-2016). Nesse mesmo espaço de tempo, houve expressiva expansão de programas nacionais de incentivo à internacionalização das universidades brasileiras promovidos pelo governo federal ${ }^{1}$.

Nosso corpus de referência é constituído de documentos institucionais de divulgação dos discursos oficiais (locais e translocais) sobre 
o tema, principalmente na mídia eletrônica ${ }^{2}$, além de editais locais para financiamento de pesquisa e chamadas para cursos e seminários direcionados para a inovação e a internacionalização da pesquisa, promovidos pela universidade focalizada no período em questão.

O mapeamento dos dados de análise foi orientado pelas seguintes perguntas mais gerais:

1. Que área(s) e tipo(s) de pesquisa aparecem em capas ou manchetes de jornais e websites institucionais e/ou são citados em editais e materiais de divulgação de programas institucionais?

2. De que modo(s) se indexam métricas locais e translocais de avaliação institucional?

Duas principais premissas teórico-metodológicas orientaram a análise do corpus de referência. A primeira é a de que a legitimação é uma ação social de natureza político-discursiva que consiste na atribuição ou no reconhecimento da legitimidade e, portanto, da aceitabilidade de determinados atores, açóes e relaçóes sociais em dado contexto normativo - no caso em exame, num contexto institucional regido por normas institucionais locais e não locais (normatizaçóes da Coordenação de Aperfeiçoamento de Pessoal de Nível Superior - CAPES — em nível nacional e normatizaçóes relativas à publicação e à mobilidade em nível internacional, por exemplo). Trata-se de uma ação de natureza políticodiscursiva na medida em que, como aponta Bourdieu (1990, p. 54):

O mundo social é o locus de lutas envolvendo as palavras, as quais devem sua seriedade - e às vezes sua violência ao fato de que palavras em grande medida fazem coisas, e que mudar as palavras, e, de modo mais geral, mudar as representações [...] já é uma maneira de mudar as coisas.

Nessa perspectiva, é interessante observar as discussóes em torno de diferenças de sentidos, tanto tidos como complementares quanto como excludentes, atribuídos ao termo internacionalização desde os anos 1990. Conforme afirma Knight (2010), como os fatores que impulsionam 
a internacionalização vêm se mostrando cada vez mais voláteis, variados, complexos e competitivos, esse é um termo a ser definido em cada contexto:

Para alguns, [internacionalização] significa uma série de actividades, tais como mobilidade acadêmica para estudantes e professores; redes internacionais, parcerias e projetos; novos programas acadêmicos e iniciativas de investigação. Para outros, significa a educação transmitida a outros países através de novos dispositivos, como campi filiais ou franquias, usando uma variedade de técnicas face-a-face e à distância. Para muitos, significa a inclusão de uma dimensão internacional e/ou global, intercultural ao currículo e aos processos locais de ensino-aprendizagem. Ainda outros veem a internacionalizaçáo como centros regionais de educação, hot spots, aldeias do conhecimento. Projetos internacionais de desenvolvimento têm sido tradicionalmente vistos como parte da internacionalizaçáo e, mais recentemente, o aumento da ênfase na comercialização do ensino superior também está sendo visto como internacionalização (KNIGHT, 2010).

Ainda em função desse caráter dinâmico, variado, complexo e competitivo das linhas de força constitutivas dos processos contemporâneos de internacionalização, torna-se relevante para a análise do corpus de referência deste artigo a premissa de que, no campo social, a legitimidade é sempre objeto de disputa e discussão, ou seja, não é um bem permanente ou estável. Em consequência, estratégias de legitimação são também estratégias de reprodução, distribuição e gerenciamento de poder naquele contexto (BOURDIEU, 1988; WODAK, 1989), sendo, por isso, estratégias de divisão e hierarquização naquele campo específico: estabelecem parâmetros para a atribuição de maior ou menor grau de legitimidade aos atores e aos discursos em circulação naquele campo.

Conforme descrito a seguir, o exame do corpus de referência aponta para uma diferença nas estratégias de legitimação das políticas de internacionalização da universidade pelos dois reitorados. O primeiro enfatiza as normatizaçóes ditadas pelas chamadas ciências duras. Portanto, associa a questáo da legitimidade à da cientificidade na produção do conhecimento e da inovação (universalidade, a-historicidade). $\mathrm{O}$ excerto 
exposto na sequência, extraído de uma entrevista publicada em 2012 com o então reitor, é ilustrativo a esse respeito:

Qualquer universidade que queira produzir conhecimento e educar de maneira semelhante ao que se faz nas boas universidades do mundo tem que ter um intercâmbio muito intenso. Não só intercâmbio de alunos de graduação ou de pós, mas também de pesquisadores e professores, e esse intercâmbio não pode ser restringir somente a visitas temporárias, mas deveria visar a atrair professores estrangeiros. Seria ideal poder trazer estudantes de fora e permitir que eles façam seu doutorado e sua pesquisa aqui (DIVULGAÇÃO AMERICAN CHAMBER OF COMMERCE, 31.08.2012).

O segundo reitorado inclui parte das ciências aplicadas, sobretudo as engenharias, no seu quadro de referências e associa a questão da legitimidade das políticas locais de internacionalização à continuidade e racionalização de uma dinâmica local própria daquela instituição (não universalidade; historicidade). A mudança de foco é assim expressa pelo então recém-empossado reitor:

Quando se fala em internacionalização, já pensamos em internacionalização para cima - quando pesquisadores de instituiçôes de ponta vêm ao país compartilhar seus conhecimentos —, mas devemos lembrar também da importância da internacionalização para baixo. [...] As universidades que estáo no topo dos rankings de qualidade sempre procuram liderar as que estão abaixo, atraindo pessoas para o seu corpo de pesquisadores [...] Além de se tornar referência nos países de origem dos pesquisadores e ficar cada vez mais conhecida, a instituição consegue obter mais mão de obra. Pesquisa exige uma infraestrutura de pessoal enorme e, ao pensarmos somente em internacionalização para cima, diminuímos a base de sustentação dos nossos projetos e, com isso, a eficiência (MAGGI, 2013).

Embora essa diferença de foco acarrete a reorganização das escalas de poder, dos posicionamentos dos atores institucionais e das prioridades de 
gestão, mantém-se a posição historicamente marginal das ciências humanas, particularmente dos estudos da língua]linguagem e na discussão e definição das políticas locais de internacionalização, inclusive das políticas linguísticas.

\section{IMPORTÂNCIA DOS RANQUEAMENTOS NA DEFINIÇÃO DAS POLÍTICAS CIENTÍFICAS DA UNIVERSIDADE}

Verificou-se que, para os dois reitorados em foco, os ranqueamentos, sobretudo os internacionais - com destaque para as posiçóes relativas da universidade focalizada no que se refere às de outras instituições brasileiras nesses mesmos rankings —, tiveram função relevante na formulação e legitimação de políticas locais de estímulo ou indução à inovação, à pesquisa e à cooperação internacional. Pode-se explicar a importância dada aos ranqueamentos como modos espetaculares de representação política, conforme aponta Rancière (2009): "A estética e a política são maneiras de organizar o sensível: de dar a entender, de dar a ver, de construir a visibilidade e a inteligibilidade dos acontecimentos".

Nesse sentido, são importantes as descrições técnicas, mesmo que sumárias, dos modos e critérios que pautaram os diferentes ranqueamentos para a produçáo de um discurso legitimador percebido como imparcial e objetivo, portanto verdadeiro e confiável, como ilustram os dois exemplos a seguir, extraídos de matérias do jornal institucional publicadas no período aqui focalizado:

A revista britânica Times Higher Education (THE) divulgou seu Ranking Mundial de Universidades de 2010-11 colocando a [Universidade Estadual de Campinas] Unicamp na $248^{\mathrm{a}}$ posição, 47 à frente da classificação de $2009\left(295^{a}\right)$. [...] As tabelas para o ranking de universidades da Times passaram a empregar 13 indicadores de performance, quando apenas seis eram utilizados anteriormente. [...] Entre os itens avaliados estáo o ambiente favorável ao aprendizado (peso de $30 \%$ ), citaçóes das pesquisas por outros autores $(32,5 \%)$, volume e reputação das pesquisas $(30 \%)$, internacionalização $(5 \%)$ e inovação $(2,5 \%)$ (SUGIMOTO, 2010). 
Nos últimos quatro anos, a Unicamp galgou 37 posiçôes no ranking global de instituições de ensino superior elaborado pela consultoria internacional Quacquarelli Symonds (QS), de acordo com o mais recente relatório "The Top Universities in the Word" [...], referente a 2016. A Universidade Estadual de Campinas agora ocupa a $191^{\text {a }}$ posição entre as mais de 900 instituiçóes ranqueadas, e é a segunda melhor avaliada no Brasil. A trajetória da Unicamp no QS manteve-se sempre ascendente. $\mathrm{O}$ avanço mais recente, entre 2015 e 2016, foi de quatro posições. [...] $\mathrm{O}$ ranking tem como base seis indicadores: reputação acadêmica (peso de 40\%); reputação no mercado de trabalho (10\%); taxa de professores por aluno $(20 \%)$; taxa de citaçóes por pesquisador $(20 \%)$; proporção de estudantes estrangeiros (5\%) e proporção de professores estrangeiros (5\%) (ORSI, 2016).

São também importantes para a adesão da comunidade ao jogo político os comentários de agentes institucionais bem posicionados nas hierarquias locais, porque reforçam tanto o caráter objetivo, imparcial e confiável dos ranqueamentos quanto a relação deles com as políticas institucionais em curso. É o que também pode ser verificado nas duas últimas matérias citadas e a seguir:

Segundo o professor Edgar De Decca, coordenador geral da Universidade, a troca da QS pela Thomson Reuters "a maior agência de notícias e multimídia do mundo" para realizar a compilação dos dados, foi decisiva para o salto da Unicamp no ranking da THE. "Pela primeira vez pudemos participar diretamente da composição das informaçôes. A CGU, com o auxílio das pró-reitorias, consolidou dados muito atualizados junto às bases da Thomson, oferecendo à agência um sólido perfil da Unicamp de hoje, em todos os níveis" (SUGIMOTO, 2010).

"Esta nova ascensão no Ranking QS confirma o posicionamento da Unicamp no seleto grupo das melhores universidades mundiais. Trata-se de um sistema de avalia- 
ção externa e independente, que analisa e pondera nossos indicadores acadêmicos. Fomos comparados com outras boas universidades, muitas delas contando com condiçóes bastante favoráveis de infraestrutura e de financiamento, e nos saímos muito bem", acrescentou o coordenador geral da Unicamp, professor Alvaro Crósta (ORSI, 2016).

Entretanto, constata-se nos discursos dos representantes institucionais do primeiro reitorado (2009-2013) mais clareza no estabelecimento de uma relação direta entre a necessidade, a urgência e a viabilidade de tais políticas e as posiçóes alcançadas nos ranqueamentos: "/na verdade, [os rankings] sáo faróis que devemos mirar em busca do nosso padrão de qualidade e excelência” (SUGIMOTO, 2010).

Nesse sentido, conforme aponta Wedlin (2014), o sucesso dos ranqueamentos está no fato de produzirem e ajudarem a produzir representaçóes tidas como verdadeiras de uma realidade e dos elementos que a constituem, ou seja, do "sensível", nos termos de Rancière (2009). Eles moldam e difundem a ideia do campo universitário como um campo global, criam medidas e meios de comparação entre as universidades e constroem a ideia da competição como chave para o sucesso e a excelência nesse campo.

Em nível local, certa hierarquização de campos e programas de pesquisa é resultante do mesmo princípio. A falta de visibilidade das ciências humanas nas políticas locais de estímulo e indução à inovação e à internacionalização da pesquisa, observada no primeiro reitorado, por exemplo, é uma consequência dessa hierarquização em função de critérios e normas próprias dos ranqueamentos tomados como referência.

Segundo relatado em uma edição do jornal institucional dedicada ao tema da inclusão da universidade "entre as melhores com menos de 50" anos:

Segundo o pró-reitor Pilli, as novas geraçóes de alunos já têm consciência de que as pesquisas devem ser divulgadas e validadas pela comunidade acadêmica. "Também é preciso aprimorar o foco dos projetos, buscando aqueles que possam gerar maior impacto no conhecimento" (LEVY, 2012, grifo nosso). 
É preciso considerar que esse impacto se traduz, na prática, por métricas de avaliação muito específicas, relacionadas à construção da visibilidade e da inteligibilidade das representaçóes do jogo político do qual fala Rancière (2009). É o que revela uma matéria publicada posteriormente no jornal institucional sobre a colaboração internacional como "alavanca" para o impacto das pesquisas feitas em instituiçóes paulistas:

As liçôes que saem deste gráfico são: a internacionalização e a colaboração internacional ajudam na visibilidade [...], disse Pedrosa. [...] "Você pode dizer que a visibilidade é medida pelo impacto, pelas citaçóes. Ela não é, necessariamente, um indicador de qualidade", adverte. "Mas indica que essa ciência está sendo mais vista, mais usada no mundo, o que no fim das contas acaba sendo um indicador de qualidade" (ORSI, 2015).

A advertência de Pedrosa no excerto anterior nos remete aos estudos críticos sobre o papel e o impacto dos ranqueamentos internacionais na configuração de um campo global de referência para a governança das universidades (HAZELKORN, 2010; SAFÓN, 2012; WEDLIN, 2014). Segundo Mohrman et al. (2008, p. 20-21), uma cuidadosa análise estatística desses ranqueamentos mostra que, se há um consenso amplo em relação às $10 \mathrm{a} 12$ primeiras posiçóes, o mesmo não acontece com as demais, pois as listas começam a divergir. E como fazem uso de apenas um pequeno número de indicadores quantitativos, os ranqueamentos acabam se baseando mais na reputaçáo, status e visibilidade acadêmica do que em um conjunto de padrōes formais estabelecidos para definir universidades "de classe mundial" (HAZELKORN, 2010; CLIMENT et al., 2013; CATTANEO et al., 2016).

\section{LEGITIMAÇÃO DAS POLÍTICAS CIENTÍFICAS EM DOIS MOVIMENTOS}

Em geral, verificou-se que o primeiro reitorado enfatizou o caráter disruptivo das políticas implementadas em relação à dinâmica habitual da instituição, apesar de reconhecer sua "vocação natural para 
a investigação científica": "Os números são respeitáveis, mas para Pilli é possível avançar ainda mais. 'Nem tanto em termos quantitativos, mas qualitativamente, diz." (LEVY, 2012).

Nessa direção, foi realçado o papel dos dirigentes institucionais (reitor e auxiliares diretos) na formulação e coordenação de políticas institucionais mais agressivas de indução e estímulo à produção científica, pautadas por parâmetros o mais próximo possível daqueles que regiam os ranqueamentos visados como alvo dessas políticas. Em consequência, as políticas locais de fomento passaram a favorecer campos, temas e metodologias de mais status e visibilidade em publicaçóes internacionais supervalorizadas segundo os parâmetros citados. As ciências humanas e as ciências aplicadas, de modo geral, não tiveram, portanto, a mesma visibilidade de outras áreas do conhecimento.

É o que explicita o entrevistado na matéria citada na seção anterior, quando se refere aos tipos de publicação que são computadas como dados nos levantamentos institucionais que se propóem a medir o grau de visibilidade da instituição pelas citaçóes:

Esses dados [...] não se aplicam tâo bem a todas as áreas. Se aplicam melhor às áreas das ciências básicas, razoavelmente bem às engenharias, à Medicina, mas às ciências humanas não se aplicam bem. [...] Então, quando a gente vai analisar por área, tem que tomar cuidado para não fazer afirmações muito fortes sobre a área de ciências humanas (ORSI, 2015).

No período referente ao segundo reitorado (2013-2016), viu-se uma espécie de reação à centralização empreendida pelo primeiro, mas sem que as demandas de internacionalizaçáo nem a importância dos ranqueamentos fossem de fato questionadas. Como antídoto à centralizaçáo excessiva, o objetivo explicitado em discursos institucionais foi dar mais espaço à participação das unidades (faculdades, institutos e centros) na definição dessas políticas.

A criação de uma vice-reitoria executiva de Relaçóes Internacionais destinada à coordenação das açóes no que tange à internacionalização, ao mesmo tempo em que se propôs a otimizar essas açóes, 
desvinculou a definição e a gestão das políticas de internacionalização da figura do reitor, evitando, assim, a percepção de uma sobreposição das políticas gerais de gestão institucional às políticas de internacionalização, como ocorrera no reitorado anterior.

Em contraposição ao discurso da ruptura (inauguração de uma nova etapa na história da instituição) adotado pelo reitorado anterior, passou-se a argumentar em favor da busca pela continuidade histórica e pela reafirmaçáo de uma vocaçáo internacional que teria caracterizado a instituição desde seus primórdios, ou seja, muito antes da globalização contemporânea. Conforme afirma o vice-reitor executivo em uma entrevista em vídeo exibida pela RTV Unicamp em 14 de maio de 2015 (INTERNACIONALIZAÇÃO DA UNICAMP, 2015), trata-se de uma universidade que, quando foi criada, “já era internacional, mesmo sem saber”, pois reuniu em seu início um grande número de professores estrangeiros. Referiu-se também ao "pioneirismo" de programas implantados antes das políticas mais recentes de internacionalização, como os de duplo diploma em Engenharia.

A pouca visibilidade das ciências humanas nos processos de definição, gestão e implementação das políticas institucionais de internacionalização permaneceu, porém, nesse segundo reitorado. Chama a atenção o caso específico dos estudos da linguagem, na medida em que o tema das barreiras linguísticas à internacionalização no Brasil e na América Latina é recorrente na literatura (GACEL-AVILA, 2007; CAMPBELL, 2015; SZUNDY, 2016; entre outros).

O destaque dado a disciplinas de ciência e tecnologia pelas políticas de internacionalização nos documentos analisados é um desdobramento da importância atribuída aos ranqueamentos, conforme descreve Hazelkorn (2010). Nos termos da autora:

As artes, as humanidades e as ciências sociais se sentem especialmente vulneráveis (o jeito mais fácil de melhorar a colocação é matar as humanidades), particularmente em instituiçôes com presença forte em ciências biomédicas e outras ciências [...]. Disciplinas profissionais, como engenharia, administração e pedagogia, que não têm tradição forte em publicaçóes com 
revisão de pares, também se encontram sob pressão. Há poucas dúvidas de que as [instituiçôes de ensino superior] IESs estão analisando os custos associados à manutenção de áreas/disciplinas consideradas menos vitais para seu perfil ou que se saiam mal em indicadores comparativos (HAZELKORN, 2010, s/p).

É ilustrativa a esse respeito a justificativa que vem na sequência, extraída de uma notícia publicada recentemente no website institucional sobre uma visita de um grupo de representantes de cinco universidades australianas classificadas entre as 50 melhores do mundo no ranking QS Top Under 50, com vistas a projetos futuros de cooperação:

São universidades focadas nas áreas de tecnologia, inovação e empreendedorismo, reconhecidas por formar profissionais que geram impacto nos setores da ciência e da tecnologia e também gestores de um futuro mais sustentável, responsáveis pela construção de uma sociedade mais consciente e com iniciativa (GARDENAL, 2016).

No caso específico dos estudos da linguagem, foi atribuído um papel instrumental ao ensino de gêneros acadêmicos escritos e de línguas estrangeiras, particularmente o inglês e o português para estrangeiros, desde o primeiro reitorado. Mas, mesmo tendo adquirido mais relevância nos discursos e nas políticas institucionais no segundo reitorado, em nenhum momento se constituiu de fato em um campo de investigação voltado para a formulação de políticas linguísticas locais específicas e capaz de produzir resultados que atendessem às necessidades criadas pelas métricas de produçáo e visibilidade da produção acadêmica em função dos ranqueamentos internacionais.

Do ponto de vista propriamente político, esse papel atribuído ao estudo da língua]linguagem é complementar às ações de legitimação das hierarquizaçôes de status e autoridade promovidas pelas políticas de internacionalização anteriormente descritas. Nos termos de Bourdieu, as açóes sociais mobilizadas por um consenso tácito, porém generalizado, acerca das regras que definem o jogo social (a noção de habitus), produzem a naturalização do status quo e o que é relevante, com a cumplicidade dos 
que mantêm posições invisíveis naquele campo específico: "Se você tiver um espírito estruturado de acordo com as estruturas do mundo no qual você está jogando, tudo lhe parecerá evidente e a própria questão de saber se o jogo vale a pena não é nem colocada” (BOURDIEU, 1996, p. 139).

\section{O PAPEL MARGINAL DOS ESTUDOS DA LINGUAGEM NA FORMULAÇÃO DAS POLÍTICAS CIENTÍFICAS LOCAIS}

Com relação a esse papel instrumental atribuído aos estudos da linguagem, foram examinados os documentos institucionais de divulgação - conforme notícias compiladas na página do Espaço da Escrita, órgão de responsabilidade da Coordenadoria Geral da universidade — de cursos de escrita científica ministrados por pesquisadores e também por editores de revistas internacionais para a comunidade acadêmica, inclusive para professores.

No que se refere ao período aqui focalizado, verificou-se que, em sua maioria, os cursos sobre escrita científica oferecidos à comunidade local foram ministrados por professores de áreas mais diretamente envolvidas com a produçáo acadêmica valorizada pelas políticas de internacionalização, como a biologia e a física, por exemplo. No mesmo período, um único curso para pós-graduandos a respeito de escrita científica em língua inglesa foi oferecido por uma professora da área de estudos da linguagem.

O exame de materiais didáticos e de aulas em vídeo apontou uma concepção de letramento acadêmico do tipo "autônomo" (STREET, 1984; KLEIMAN, 1995), ou seja, articulado em função de componentes propriamente textuais e desvinculado das práticas de leitura, produção e circulação de materiais escritos que de fato permeiam as atividades científicas. Em consequência, ao mesmo tempo em que são enfatizados modelos formais de caráter normativo, são também destacados os riscos de plágio e a falta de criatividade como fatores que podem inviabilizar a publicação de resultados em veículos que de fato interessam às políticas institucionais.

No caso da escrita em língua estrangeira e considerando as dificuldades por parte da comunidade local, e náo apenas discente, com o inglês, esse modo de compreensão e abordagem do letramento acadêmico tem se mostrado pouco produtivo, pois, como bem assinalam estudiosos dos letramentos acadêmicos: 
Nenhum curso geral de Inglês, nem mesmo um especializado em escrita científica, nem mesmo um que use materiais e tarefas autênticas, pode proporcionar suficiente profundidade na língua daquela especialidade. Nem pode qualquer curso proporcionar horas suficientes de prática motivada e desafios suficientes para desenvolver o nível de competência e fluência necessários para a participação de alto nível numa especialidade em Inglês. Cursos de línguas só podem fornecer preparação e apoio para facilitar a prática real em situações de imersão, mas em algum momento, essas situaçôes deverão tornar-se o locus da prática da escrita (BAZERMAN et al., 2012, p. 235).

No caso dos cursos aqui focalizados, é preciso compreender situações de imersão como situações de imersão do aprendiz em práticas de produção científica envolvendo diferentes gêneros e modos de circulação de materiais escritos que vão compor a expertise letrada naquele campo específico e culminar na publicação dos gêneros de mais prestígio naquele campo. O foco estaria, pois, no processo, e não no produto desse processo como alvo principal do ensino.

\section{CONSIDERAÇÕES FINAIS}

Foram focalizadas, neste artigo, as estratégias de legitimação de políticas científicas voltadas para a internacionalização de uma universidade pública paulista no período compreendido pelos dois últimos reitorados (2009-2016). Conforme apontado, tais estratégias tiveram também a função de legitimação da gestão e de reprodução do poder institucional e, consequentemente, de reprodução da hierarquização de atores e discursos dentro da instituição. Nessa hierarquização, orientada por critérios e normas próprias dos ranqueamentos internacionais, tidos como imparciais e objetivos, manteve-se a posição historicamente marginal das ciências humanas, particularmente dos estudos da linguagem, nos processos de definição e implementação das políticas locais de internacionalização, inclusive das políticas linguísticas. 


\section{REFERÊNCIAS}

BAZERMAN, C.; KERANEN, N.; ENCINAS, F. Facilitated immersion at a distance in second language scientific writing. In: CASTELLÒ, M.; DONAUHE, C. (Eds.) University writing: selves and texts in academic societies. London, Emerald Group, p. 235-248, 2012.

BOURDIEU, P. In Other Words: essays towards a reflexive sociology. Cambridge: Polity, 1990.

BOURDIEU, P. Razões Práticas: Sobre a teoria da ação. Campinas: Ed. Papirus, 1996.

BOURDIEU, P. Language and Symbolic Power. Cambridge: Polity Press, 1988.

CAMPBELL, K. Bilateral student mobility in Brazil: language as a doubleedged sword in internationalization. Journal of International Mobility, v. 1, p. 129-146, 2015. DOI: 10.3917/jim.001.0129

CATTANEO, M., MEOLI, M., \& PALEARI, S. Why do universities internationalize? Organizational reputation and legitimacy. In D. L. Audretsch, E., Meoli, M., Vismara, S. (ed.), University Evolution, Entrepreneurial Activity and Regional Competitiveness. Dordrecht: Springer, p. 2016, p. 327-346.

CLIMENT, V.; MICHAVILA, F.; RIPOLLES, M. (Orgs.). Los rankings univeritarios: mitos y realidades. Madri: Tecnos, 2013.

DIVULGAÇÃO AMERICAN CHAMBER OF COMMERCE. Os desafios da inovação no campo universitário. Unicamp Notícias, 31 ago. 2012. Disponível

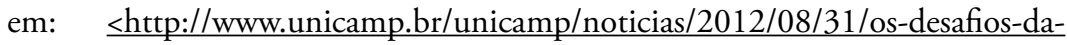
inovacao-no-campo-universitario $>$. Acesso em: 18 jan. 2017.

Espaço da Escrita. Disponível em: <https://www.prp.unicamp.br/pt-br/espacoda-escrita>. Acesso em: 08 maio 2018.

GACEL-AVILA, J. The Process of Internationalization of Latin American Higher Education. Journal of Studies in International Education, v. 11, n. 3-4, p. 400-409, 2007. https://doi.org/10.1177/1028315307303921

GARDENAL,A. Unicamp egrupo ATN estudam parceria futura. Unicamp Notícias, 17 nov. 2016. Disponível em: $\leq$ https://www.unicamp.br/unicamp/noticias/2016/11/30/ unicamp-e-grupo-atn-estudam-parceria-futura $>$. Acesso em: 18 jan. 2017.

HAZELKORN, E. Os rankings e a batalha por excelência de classe mundial: estratégias institucionais e escolhas de políticas. Revista Ensino Superior UNICAMP, 
2010. Disponível em: <https://www.revistaensinosuperior.gr.unicamp.br/ artigos/os-rankings-e-a-batalha-por-excelencia-de-classe-mundial-estrategiasinstitucionais-e-escolhas-de-politicas $>$. Acesso em: 18 jan. 2017.

INTERNACIONALIZAÇÃO DA UNICAMP. Palavras Cruzadas. Campinas: RTV Unicamp, 14 maio 2015. Disponível em: <http://www.rtv.unicamp. br/?video listing=internacionalizacao-da-unicamp $>$. Acesso em: 18 jan. 2017.

KLEIMAN, A.B. (Org.). Os Significados do Letramento. Campinas: Mercado de Letras, 1995.

KNIGHT, J. Internacionalización de la educación superior: nuevos desarrollos y consecuencias no intencionadas. Boletín Iesalc Informa, n. 211, 2010. Disponível em: shttp://www.iesalc.unesco.org.ve/index.php?option=com content\&view $=$ article\&id $=2418 \% 3$ Ainternacionalizacion-de-la-educacion-superior-nuevosdesarrollos-y-consecuencias-no-intencionadas $\&$ catid $=126 \% 3$ Anoticias-paginanueva\&Itemid=712\&lang=es $>$. Acesso em: 18 jan. 2017.

LEVY, C. Relação entre ensino e pesquisa é diferencial. Jornal da Unicamp, n. 529, de 11-17 jun. 2012. Disponível em: <https://issuu.com/ascom.unicamp/ docs/ju529>. Acesso em: 18 jan. 2017.

MAGGI, L. "A Unicamp deve promover internacionalização para baixo". Veja Educação, 06 maio 2013. Disponível em: shttp://veja.abril.com.br/educacao/aunicamp-deve-promover-internacionalizacao-para-baixo/>. Acesso em: 18 jan. 2017.

MOHRMAN, K.; WANHUA, M.A.; BAKER, D. The research university in transition: the emerging global model. Higher Education Policy, v. 21, n. 1, p. 5-27, 2008.

ORSI, C. Colaboração internacional alavanca impacto de pesquisas feitas em SP. Jornal da Unicamp, n. 644, 16-29 nov. 2015. Disponível em: <http://www. unicamp.br/unicamp/ju/644/colaboracao-internacional-alavanca-impacto-depesquisas-feitas-em-sp $>$. Acesso em: 18 jan. 2017.

RANCIÈRE, J. Entrevista. Revista Cult, n. 139, 2009. Disponível em: https:// revistacult.uol.com.br/home/entrevista-jacques-ranciere/ Acesso em: 17 abril 2018

SAFÓN, V. Análisis de los factores subyacentes en los rankings internacionales de universidades. Regional and Sectoral Economic Studies, v. 12, n. 3, 2012.

STREET, B.V. Literacy in Theory and Practice. Cambridge, Nova York e Melbourne: Cambridge University Press, 1984. 
SUGIMOTO, L. Unicamp sobe 47 posiçóes na THE World University Rankings. Jornal da Unicamp, 16 set. 2010. Disponível em: $\leq$ http://www.unesp. br/aci/clipping/exibe.php? 16,09,2010,bd\#ext-0.61162400\%201284725955>. Acesso em: 18 jan. 2017.

SZUNDY, P.T.C. The commodification of English in Brazilian public universities: language ideologies entextualized in the scope of the program English without Borders. Revista da Anpoll, v. 1, n. 40, p. 101-114, 2016. https://doi.org/10.18309/anp.v1i40.1020

Unicamp sobe em ranking QS. Universidade ocupa a $191^{\text {a }}$ posição entre as mais de 900 instituiçóes avaliadas. Jornal da Unicamp, n. 668, 9-18 set. 2016. Disponível em: <http://www.unicamp.br/unicamp/ju/668/unicamp-sobe-emranking-qs $>$. Acesso em: 08 maio 2018.

WEDLIN, L. How global comparisons matter: the 'truths' of international rankings. Bibliometrics. Use and Abuse in the Review of Research Performance. Portland Press Limited, p. 65-75, 2014.

WODAK, R. (Org.). Language, power and ideology: studies in political discourse. Amsterdã: Benjamins, 1989.

\section{NOTAS}

1. Com destaque para o Programa Ciência sem Fronteiras, extinto recentemente, cujo objetivo era "promover a consolidação, expansão e internacionalização da ciência e tecnologia, da inovaçáo e da competitividade brasileira por meio do intercâmbio e da mobilidade internacional". Informaçóes disponíveis em: <http://www. cienciasemfronteiras.gov.br/web/csf/o-programa>. Acesso em: 22 jan. 2017).

2. Foram consultados documentos exibidos em websites e revistas institucionais, entrevistas publicadas de reitores e pró-reitores (vídeo e texto) e o jornal eletrônico de divulgação de dissertaçôes, teses e outras produçôes científicas da instituição no período focalizado (conforme endereços listados na seçáo Referências).

Recebido em 02 de agosto de 2017. Aceito em 23 de março de 2018. 